\title{
Continuous-flow left ventricular assist device versus orthotopic heart transplantation in adults with heart failure: a systematic review and meta-analysis
}

\author{
Bufan Zhang ${ }^{1 \#}$, Shaohua Guo ${ }^{2 \#}$, Jie Ning ${ }^{3 \#}$, Yiai Li ${ }^{4}$, Zhigang Liu ${ }^{1,4}$ \\ ${ }^{1}$ Department of Cardiovascular Surgery, TEDA International Cardiovascular Hospital, Cardiovascular Clinical College of Tianjin Medical \\ University, Tianjin, China; ${ }^{2}$ Tianjin Key Laboratory of Ionic-Molecular Function of Cardiovascular Disease, Department of Cardiology, Tianjin \\ Institute of Cardiology, Second Hospital of Tianjin Medical University, Tianjin, China; ${ }^{3}$ Department of Health Administration, School of Medicine \\ and Health Management, Tongji Medical College, Huazhong University of Science and Technology, Wuhan, China; ${ }^{4}$ Department of Cardiovascular \\ Surgery, TEDA International Cardiovascular Hospital, Chinese Academy of Medical Sciences \& Peking Union Medical College, Tianjin, China \\ \#These authors contributed equally to this work. \\ Correspondence to: Zhigang Liu, MD. Department of Cardiovascular Surgery, TEDA International Cardiovascular Hospital, 61 Third Avenue, TEDA, \\ Tianjin 300457, China. Email: liuzg@tedaich.com.
}

Background: Due to the lack of donor hearts, many studies have assessed the prognosis of heart failure (HF) patients treated with a continuous-flow left ventricular assist device (CF-LVAD). However, previous results have not been consistent and minimal data is available regarding long-term outcomes. There is no consensus on whether CF-LVAD as a bridge or destination therapy (DT) can equal orthotopic heart transplantation (HTx). The purpose of our study is to compare clinical outcomes between CF-LVAD and HTx in adults.

Methods: We searched controlled trials from PubMed, Cochrane Library, and Embase databases until July 1, 2020. The mortality at different time points and adverse events were analyzed among 12 included studies. Results: No significant differences were found in mortality at one-year [odds ratio (OR) $=1.08 ; 95 \%$ CI: $0.97-1.21$ ], two-year (OR $=1.01 ; 95 \% \mathrm{CI}: 0.91-1.12$ ), three-year (OR =1.02; 95\% CI: 0.69-1.51), and five-year ( $\mathrm{OR}=1.02 ; 95 \% \mathrm{CI}$ : 0.93-1.11), as well as the comparison of stroke, bleeding, and infection between CF-LVAD as a bridge versus HTx. The pooled analysis of one-year mortality (OR =2.76; 95\% CI: $0.38-20.18)$ and two-year mortality (OR $=1.64$; 95\% CI: $0.22-12.23$ ) revealed no significant difference between CF-LVAD DT and HTx. Comparisons of adverse events showed no differences in bleeding or infection, but a higher risk of stroke (OR =5.09; 95\% CI: 1.74-14.84) for patients treated with CF-LVAD DT than with HTx.

Conclusions: CF-LVAD as a bridge results in similar outcomes as HTx within five years. CF-LVAD as a DT is associated with similar one-year and two-year mortality, but carries a higher risk of stroke, as compared with HTx.

Keywords: Heart failure (HF); continuous-flow left ventricular assist device (CF-LVAD); heart transplantation (HTx); bridge to transplantation (BTT); destination therapy (DT)

Submitted Sep 10, 2020. Accepted for publication Dec 17, 2020.

doi: 10.21037/acs-2020-cfmcs-fs-197

View this article at: http://dx.doi.org/10.21037/acs-2020-cfmcs-fs-197

ㄷ Annals of Cardiothoracic Surgery. All rights reserved. Ann Cardiothorac Surg 2021;10(2):209-220 I http://dx.doi.org/10.21037/acs-2020-cfmcs-fs-197 


\section{Introduction}

Heart failure (HF), as a leading global disease, is an advanced clinical stage of cardiovascular disease with severe cardiac dysfunction. It is estimated that over 37.7 million people worldwide suffer from HF, the incidence and mortality of which continue to increase (1). Although orthotopic heart transplantation (HTx) is indeed an effective treatment, it cannot satisfy the demands of patients due to the paucity of and prolonged waiting time for donor hearts (2).

The left ventricular assist device (LVAD), including pulsatile-flow LVAD and continuous-flow left ventricular assist device (CF-LVAD), has been widely used because it significantly reduces mortality and improves quality of life, as compared to medical therapy alone $(3,4)$. Pulsatileflow LVADs mainly refer to first-generation LVADs, such as Heartmate XVE and Novacor (5). With the gradual advancement of equipment, CF-LVADs have since become the main LVADs, due to their miniaturization and improved durability, including those of second- and third-generation devices. Second-generation LVADs, like Heartmate II, pump blood through axial-flow technology (6), while thirdgeneration LVADs apply a centrifugal-flow pattern with magnetically levitated forces, including Heartmate III and Heartware HVAD $(7,8)$. However, there is no clear and consistent understanding of the longer therapeutic effects of CF-LVAD and HTx $(2,9)$. We conducted a systematic review and meta-analysis to compare the clinical outcomes of HTx and CF-LVAD as a bridge to transplantation (BTT) or destination therapy (DT). According to our analytic results, we discuss the future direction of HF treatment.

\section{Methods}

\section{Search strategy and selection criteria}

The systematic review and meta-analysis of observational studies was performed in accordance with the Meta-analysis of Observational Studies in Epidemiology (MOOSE) guidelines (10). We searched controlled trials from PubMed, Cochrane Library, and Embase databases until July 1, 2020. The language was limited to English. The specific searching strategy was as follows: ("heart failure" OR "cardiac failure" OR "heart decompensation" OR "decompensation, heart" OR "myocardial failure") AND ("heart-assist devices" OR "heart assist device" OR "artificial heart" OR "device, heart-assist" OR "devices, heart-assist" OR "heart assist devices" OR "heart-assist device" OR "pumps, heart-assist"
OR "heart-assist pump" OR "heart-assist pumps" OR "pump, heart-assist" OR "pumps, heart assist" OR "artificial ventricle" OR "artificial ventricles" OR "ventricle, artificial" OR "ventricles, artificial" OR "ventricle-assist device" OR "device, ventricle-assist" OR "devices, ventricle-assist OR "ventricle assist device" OR "ventricle-assist devices" OR "ventricular assist device" OR "assist device, ventricular" OR "assist devices, ventricular" OR "device, ventricular assist" OR "devices, ventricular assist" OR "ventricular assist devices" OR "heart ventricle, artificial" OR "artificial heart ventricle" OR "artificial heart ventricles" OR "heart ventricles, artificial" OR "ventricle, artificial heart" OR "ventricles, artificial heart" OR "LVAD" OR "left ventricular assist device" OR "VAD" OR "mechanical circulatory support" OR "mechanical circulatory support device" OR "mechanical circulatory support devices") AND ("heart transplantation" OR "heart transplant" OR "cardiac transplant" OR "grafting, heart" OR "graftings, heart" OR "heart grafting" OR "heart graftings" OR "transplantation, heart" OR "heart transplantations" OR "transplantations, heart" OR "cardiac transplantation" OR "cardiac transplantations" OR "transplantations, cardiac" OR "transplantation, cardiac).

The trials were based on the following inclusion criteria: (I) cohort and controlled trials comparing orthotopic HTx with CF-LVAD as a BTT or DT; (II) trials respectively reported mortality or survival data of different groups; (III) whether CF-LVAD was used as a BTT or DT was clearly stated; (IV) only the study with more patients should be included if two or more studies from the same institution have reported duplicate outcomes. The exclusion criteria were: (I) the study population was mainly composed of infants or children; (II) study did not perform a headto-head comparison; (III) research focused mainly on pulsatile-flow LVADs or total artificial heart; (IV) lowquality abstracts or articles without impact factors. Two authors (B.Z. and S.G.) scrutinized all examined articles independently and disagreements were resolved by discussing with an external third author (Z.L.).

\section{Quality assessment and data extraction}

The following data was collected: first author, year of publication, country, study design, study period, baseline characteristics (gender, etiology, the sample size of each group), the type of LVAD, and follow-up period. We extracted the original data of the follow-up period from Kaplan-Meier survival curves, if they could not be obtained 


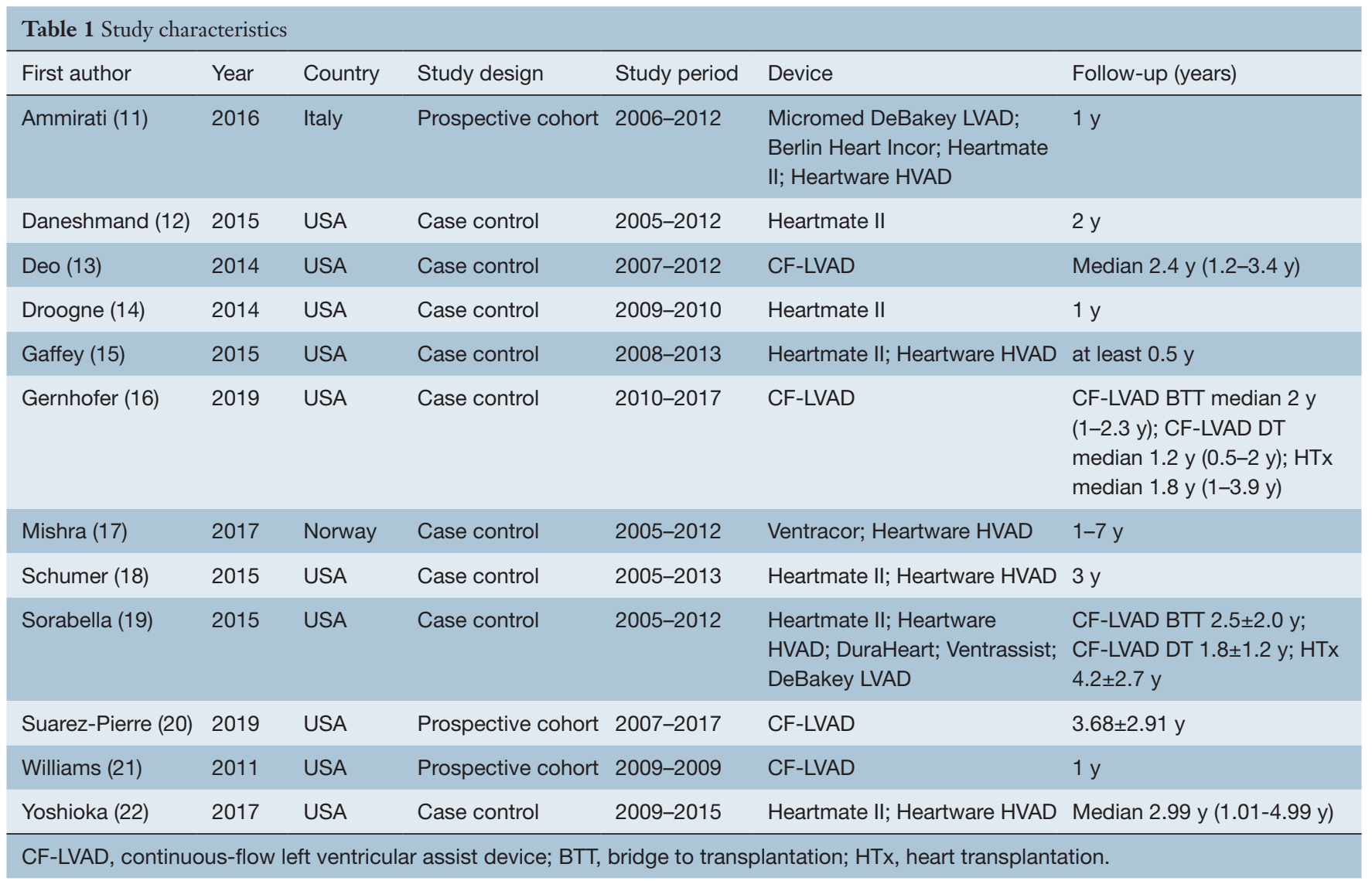

from the original article. According to the survival rate or mortality, we calculated the number of deaths at different time points in each group. Table 1 and Table 2 detail the specific data of each study. The quality of the included literature was assessed according to the Newcastle-Ottawa Scale (NOS). This scale was divided into three parts: selection (4 points), comparability (2 points), and outcome (3 points), including 7-9 points for low risk, 4-6 points for medium risk, and 0-3 points for high risk. The details of the NOS quality assessment are shown in Table S1. Two researchers (B.Z. and S.G.) separately performed a quality assessment and data extraction. Any conflicts were resolved by consensus and further discussion with a third reviewer (Z.L.).

\section{Data analysis}

We set various time points to evaluate mortality more accurately. One-year, two-year, three-year, and five-year mortality rates were analyzed in the comparison of $\mathrm{CF}$ LVAD BTT versus HTx, while one-year and two-year mortality were analyzed in the comparison of CF-LVAD DT versus HTx. The primary outcomes were mortality at different time points. In addition, the adverse events of CF-LVAD versus HTx were also analyzed, including stroke, bleeding, and infection. BTT included patients undergoing a CF-LVAD to preserve life, who would otherwise be at high risk of death before transplantation unless a donor organ were to become available. DT was defined as using a CF-LVAD as an alternative to HTx in patients ineligible for transplantation or on the waiting list for a donor heart over an extensive time period. Stroke included post-operative ischemic and hemorrhagic cerebrovascular accidents. Bleeding was defined as perioperative hemorrhage requiring re-operation. Infection was defined as deep sternal infection or sepsis. The data results of dichotomous variables are present as pooled odds ratios (OR) with 95\% confidence intervals (CI). We used the $I^{2}$ test to assess the heterogeneity among the studies. The heterogeneity was considered significant if $I^{2}$ was $>50 \%$. A fixed-effects model was used if no significant heterogeneity was detected; otherwise, a random-effects model was used 


\begin{tabular}{|c|c|c|c|c|c|}
\hline Ammirati 2016 (11) & 73.2 & 22 & - & 164 & NA \\
\hline Daneshmand 2015 (12) & 75 & - & 146 & 62 & Ischemic heart disease, other \\
\hline Deo 2014 (13) & 69.8 & 37 & - & 69 & Ischemic heart disease, other \\
\hline Gaffey 2015 (15) & 71.8 & 72 & - & 116 & $\begin{array}{l}\text { Idiopathic cardiomyopathy, ischemic heart } \\
\text { disease, congestive heart failure, other }\end{array}$ \\
\hline Gernhofer 2019 (16) & 89.5 & 29 & 41 & 25 & $\begin{array}{l}\text { Ischemic heart disease, non-ischemic heart } \\
\text { disease }\end{array}$ \\
\hline Mishra 2017 (17) & 74.1 & 26 & 19 & 206 & DCM, ischemic heart disease, other \\
\hline Sorabella 2015 (19) & 91.2 & - & 23 & 47 & $\begin{array}{l}\mathrm{DCM}, \mathrm{RCM} \text {, valvular disease, ischemic heart } \\
\text { disease, other }\end{array}$ \\
\hline Suarez-Pierre 2019 (20) & 73.7 & 5,584 & - & 12,295 & $\mathrm{DCM}, \mathrm{RCM}, \mathrm{CHD}$, ischemic heart disease, other \\
\hline Williams 2011 (21) & 90.5 & 29 & - & 13 & NA \\
\hline Yoshioka 2017 (22) & 72.6 & 130 & - & 246 & $\begin{array}{l}\mathrm{DCM}, \mathrm{ICM}, \mathrm{HCM}, \mathrm{RCM}, \mathrm{CHD} \text {, valvular disease, } \\
\text { other }\end{array}$ \\
\hline
\end{tabular}

to pool the data. We evaluated publication bias with Egger's test for primary outcomes. An absence of publication bias was considered when the $\mathrm{P}$ value was $>0.05$. We conducted subgroup analyses, sensitivity analysis, and meta-regression to evaluate the influence of individual studies and potential sources of heterogeneity. We performed statistical analysis with Review Manager 5.3 and Stata 16.

\section{Results}

\section{Included studies}

In total, 16,988 publications were identified from the three databases, twelve of which (11-22) met the inclusion criteria (details shown in Figure 1). Four studies $(14,16,17,19)$ simultaneously reported data on BTT versus HTx and DT versus $H T x$, while seven trials $(11,13,15,18,20-22)$ only showed the results of BTT versus HTx, and one study (12) performed the comparison of DT versus HTx alone. Yoshioka et al. (22) and Sorabella et al. (19) are from the same institution and have both reported on data of CF-
LVAD BTT versus HTx. Therefore, 10 of the eligible studies (11,13-18,20-22) were included in the comparison of CF-LVAD BTT versus HTx, and five of them $(12,14,16,17,19)$ reported on the results of CF-LVAD DT versus HTx. A total of 26,737 patients (8,503 underwent CF-LVAD as a BTT, 235 underwent CF-LVAD as a DT, 17,999 underwent HTx) were included in our research for quantitative analysis of post-operative adverse events and mortality at different time points. No publication bias for primary outcomes was presented, according to Egger's test (Figure S1).

\section{The mortality of CF-LVAD BTT versus HTx}

There was no significant difference in the one-year (OR $=1.08 ; 95 \%$ CI: $0.97-1.21 ; \mathrm{P}=0.15 ; I^{2}=0 ;$ Figure $2 A$ ), two-year $\left(\mathrm{OR}=1.01 ; 95 \% \mathrm{CI}: 0.91-1.12 ; \mathrm{P}=0.87 ; I^{2}=0\right.$; Figure $2 B)$, three-year $(\mathrm{OR}=1.02 ; 95 \%$ CI: $0.69-1.51$; $\mathrm{P}=0.93 ; I^{2}=26 \%$; Figure $\left.2 C\right)$, and five-year $(\mathrm{OR}=1.02 ; 95 \%$ CI: $0.93-1.11 ; \mathrm{P}=0.75 ; I^{2}=0$; Figure $2 D$ ) mortality between CF-LVAD BTT and HTx. 


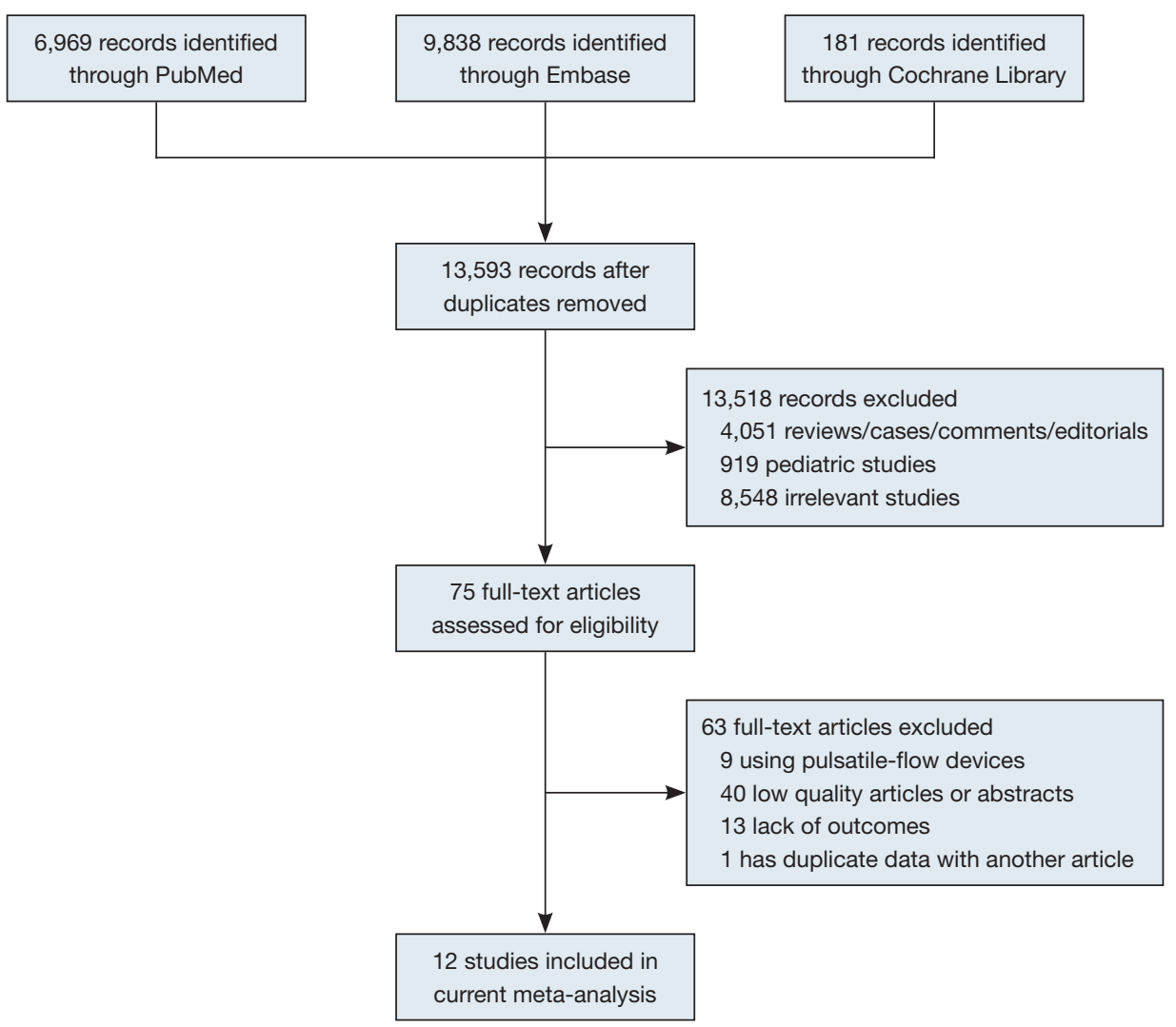

Figure 1 Flow chart of the study selection process.

\section{Adverse events of CF-LVAD BTT versus HTx}

No significant differences were found in stroke $(\mathrm{OR}=4.63$; 95\% CI: 0.72-29.86; $\mathrm{P}=0.11 ; I^{2}=0$; Figure $3 A$ ), bleeding $\left(\mathrm{OR}=1.65 ; 95 \%\right.$ CI: $0.79-3.46 ; \mathrm{P}=0.19 ; I^{2}=0 ;$ Figure $\left.3 B\right)$, and infection $\left(\mathrm{OR}=1.74 ; 95 \% \mathrm{CI}: 0.86-3.52 ; \mathrm{P}=0.12 ; I^{2}=0\right.$; Figure $3 C$ ) in the comparison of CF-LVAD BTT versus HTx.

\section{The mortality of CF-LVAD DT versus HTx}

The pooled analysis of one-year mortality ( $\mathrm{OR}=2.76 ; 95 \%$ CI: $0.38-20.18 ; \mathrm{P}=0.32 ; I^{2}=81 \%$; Figure $4 A$ ) and two-year mortality (OR $=1.64 ; 95 \%$ CI: $0.22-12.23 ; \mathrm{P}=0.63 ; I^{2}=89 \%$; Figure $4 B$ ) showed no significant difference between CFLVAD DT and HTx. According to the country, subgroup analysis was performed due to high heterogeneity in oneyear mortality. In the USA group, there was no significant difference in one-year mortality $(\mathrm{OR}=1.04 ; 95 \% \mathrm{CI}$ : $0.32-3.32 ; \mathrm{P}=0.95 ; I^{2}=0$; Figure $4 A$ ). Regarding two-year mortality, sensitivity analysis and meta-regression did not identify any determinants that were able to explain the heterogeneity (Figure S2).

\section{Adverse events of CF-LVAD DT versus HTx}

The incidence of stroke (OR $=5.09 ; 95 \%$ CI: 1.74-14.84; $\mathrm{P}=0.003 ; I^{2}=0 ;$ Figure $5 A$ ) was higher for CF-LVAD DT than for HTx. There was no significant difference in bleeding (OR $=0.81 ; 95 \%$ CI: $0.28-2.38 ; \mathrm{P}=0.70 ; I^{2}=35 \%$; Figure $5 B$ ) or infection rates (OR $=0.69 ; 95 \%$ CI: $0.34-1.43$; $\mathrm{P}=0.32 ; I^{2}=0$; Figure $5 C$ ) in the comparison of CF-LVAD DT versus HTx.

\section{Discussion}

To our knowledge, this study is the first meta-analysis to compare clinical outcomes between CF-LVAD and HTx for the treatment of patients with HF. CF-LVADs have become the main application in use, so the pulsatile-flow pumps were excluded, which was not considered in previous 


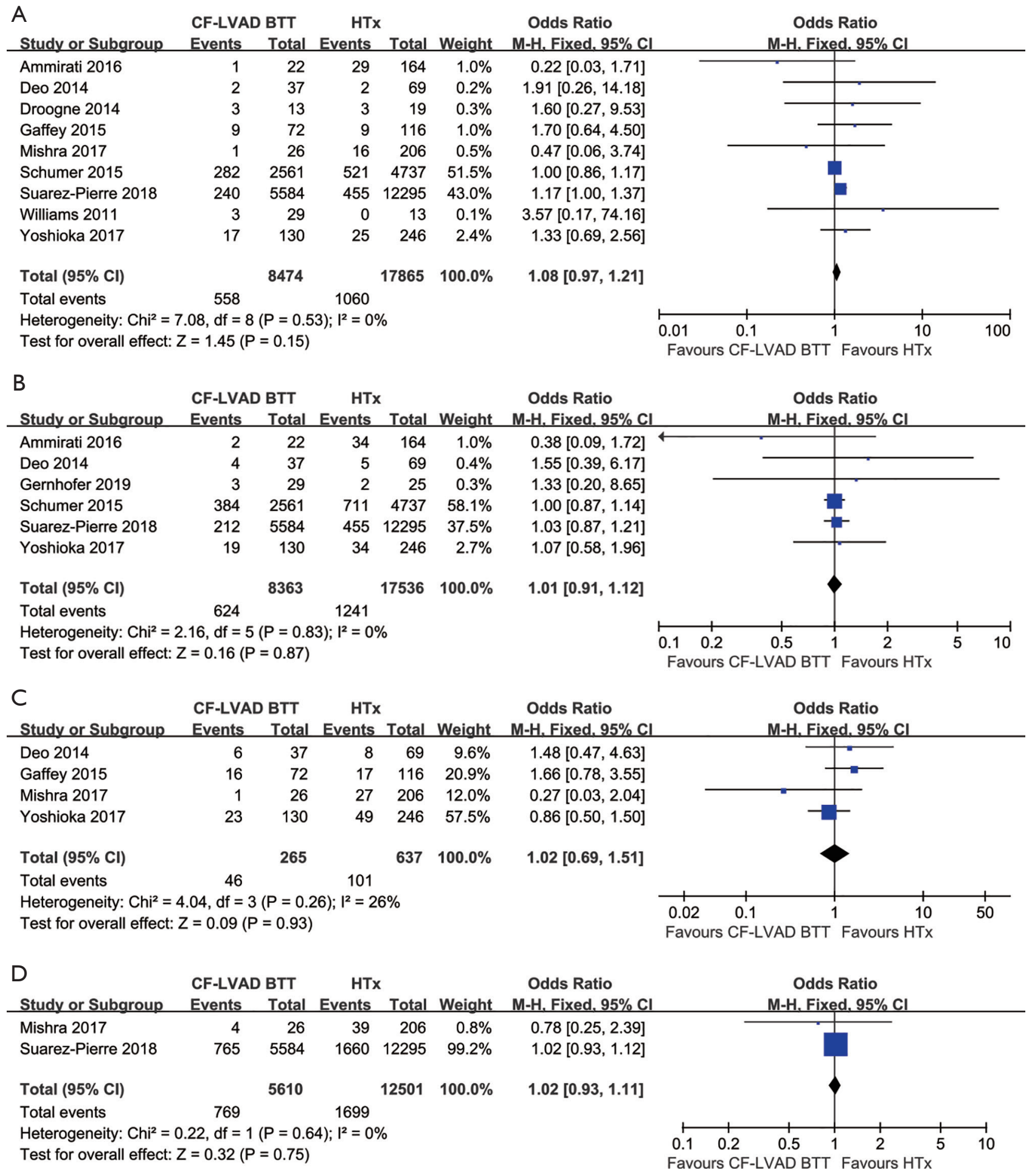

Figure 2 Forest plots for the mortality between CF-LVAD BTT vs. HTx. (A) One-year mortality, (B) two-year mortality, (C) three-year mortality, and (D) five-year mortality. CF-LVAD, continuous-flow left ventricular assist device; BTT, bridge to transplantation; HTx, heart transplantation; OR, odds ratio; CI, confidence interval. 


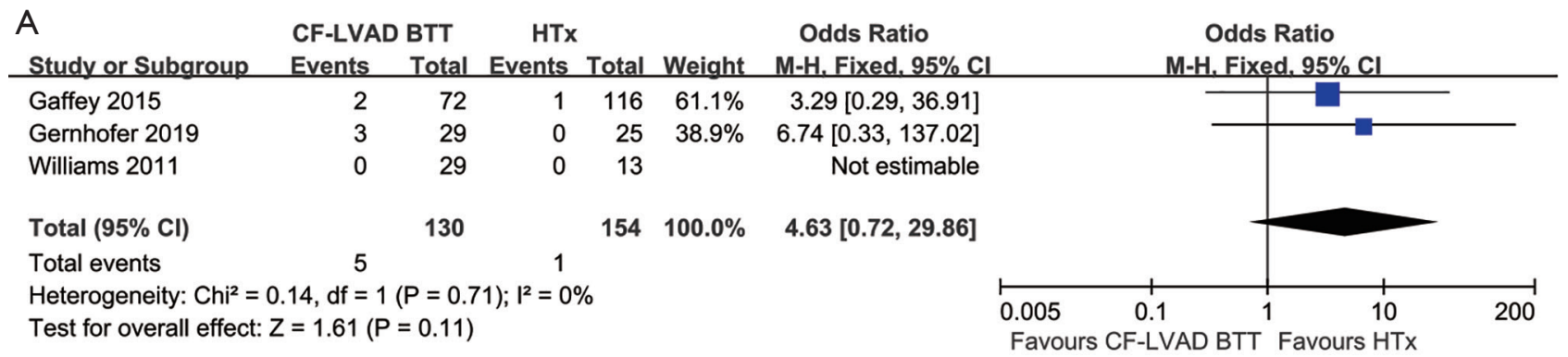

B

\begin{tabular}{lrrrrr} 
Study or Subgroup & Events & Total & Events & Total & Weight \\
\hline Deo 2014 & 0 & 37 & 3 & 69 & $22.4 \%$ \\
Gaffey 2015 & 10 & 72 & 8 & 116 & $48.6 \%$ \\
Gernhofer 2019 & 3 & 29 & 1 & 25 & $8.9 \%$ \\
Williams 2011 & 6 & 29 & 2 & 13 & $20.2 \%$ \\
& & & & & \\
Total $(95 \% \mathrm{Cl})$ & 19 & & 14 & \\
Total events & & & & \\
Heterogeneity: Chi $^{2}=2.03, \mathrm{df}=3(\mathrm{P}=0.57) ;\left.\right|^{2}=0 \%$ \\
Test for overall effect: $\mathrm{Z}=1.32(\mathrm{P}=0.19)$
\end{tabular}

Odds Ratio Odds Ratio

M-H. Fixed. 95\% Cl

$0.25[0.01,5.04]$

$2.18[0.82,5.81]$

$2.77[0.27,28.47]$

$1.43[0.25,8.29]$

$1.65[0.79,3.46]$

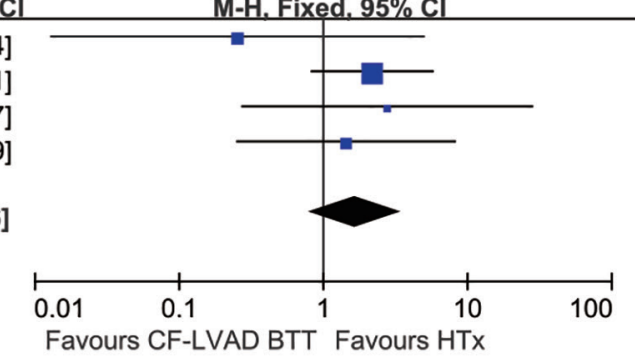

C

\begin{tabular}{lrrrrr} 
Study or Subgroup & Events & Total & Events & Total & Weight \\
\hline Deo 2014 & 8 & 37 & 7 & 69 & $33.1 \%$ \\
Gaffey 2015 & 3 & 72 & 2 & 116 & $12.7 \%$ \\
Gernhofer 2019 & 16 & 29 & 13 & 25 & $54.2 \%$ \\
Williams 2011 & 0 & 29 & 0 & 13 & \\
& & & & & \\
Total $(95 \% \mathrm{Cl})$ & 27 & & 223 & $100.0 \%$ \\
Total events & 27 & & \\
Heterogeneity: Chi $^{2}=1.11, \mathrm{df}=2(\mathrm{P}=0.57) ; I^{2}=0 \%$ \\
Test for overall effect: $\mathrm{Z}=1.54(\mathrm{P}=0.12)$
\end{tabular}

Odds Ratio Odds Ratio

M-H. Fixed, 95\% Cl

$2.44[0.81,7.38]$

$2.48[0.40,15.20]$

$1.14[0.39,3.32]$

Not estimable

$1.74[0.86,3.52]$

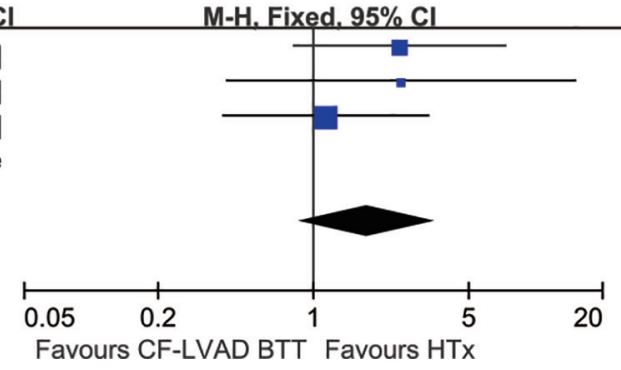

Figure 3 Forest plots for the adverse events between CF-LVAD BTT vs. HTx. (A) Stroke, (B) bleeding, and (C) infection. CF-LVAD, continuous-flow left ventricular assist device; BTT, bridge to transplantation; HTx, heart transplantation; OR, odds ratio; CI, confidence interval.

meta-analyses. Additionally, all the included studies were from institutions that could perform both CF-LVAD implantation and HTx in order to avoid the influence of external interests. The opinions of the included studies were discrepant, so the factors that affect HF patients' prognosis were discussed from various perspectives.

No significant differences were found in both mortality at different time points and adverse events between HTx and CF-LVAD BTT. However, previous reported mortality or survival rates differ among current studies $(11,15,23,24)$, in the comparison of HTx and CF-LVAD BTT. The reasons behind any inconsistencies in results within this meta-analysis are as follows. First, the duration of LVAD support differed among the included studies, for the time of HTx after CF-LVAD as a bridge depends significantly on when donors are available. Excessive duration of LVAD as a bridge may reduce patient survival (25). Secondly, the evaluation and utilization of marginal donors vary among medical centers and experts (26), although LVAD as a BTT has positive effects on the avoidance of marginal donor hearts. Thirdly, there was selection bias between groups among observational studies. In other words, more severely ill patients were less likely to survive if they had received HTx instead of CF-LVAD as a BTT at that time (27). Overall, CF-LVAD BTT can bring excellent outcomes comparable to HTx. 


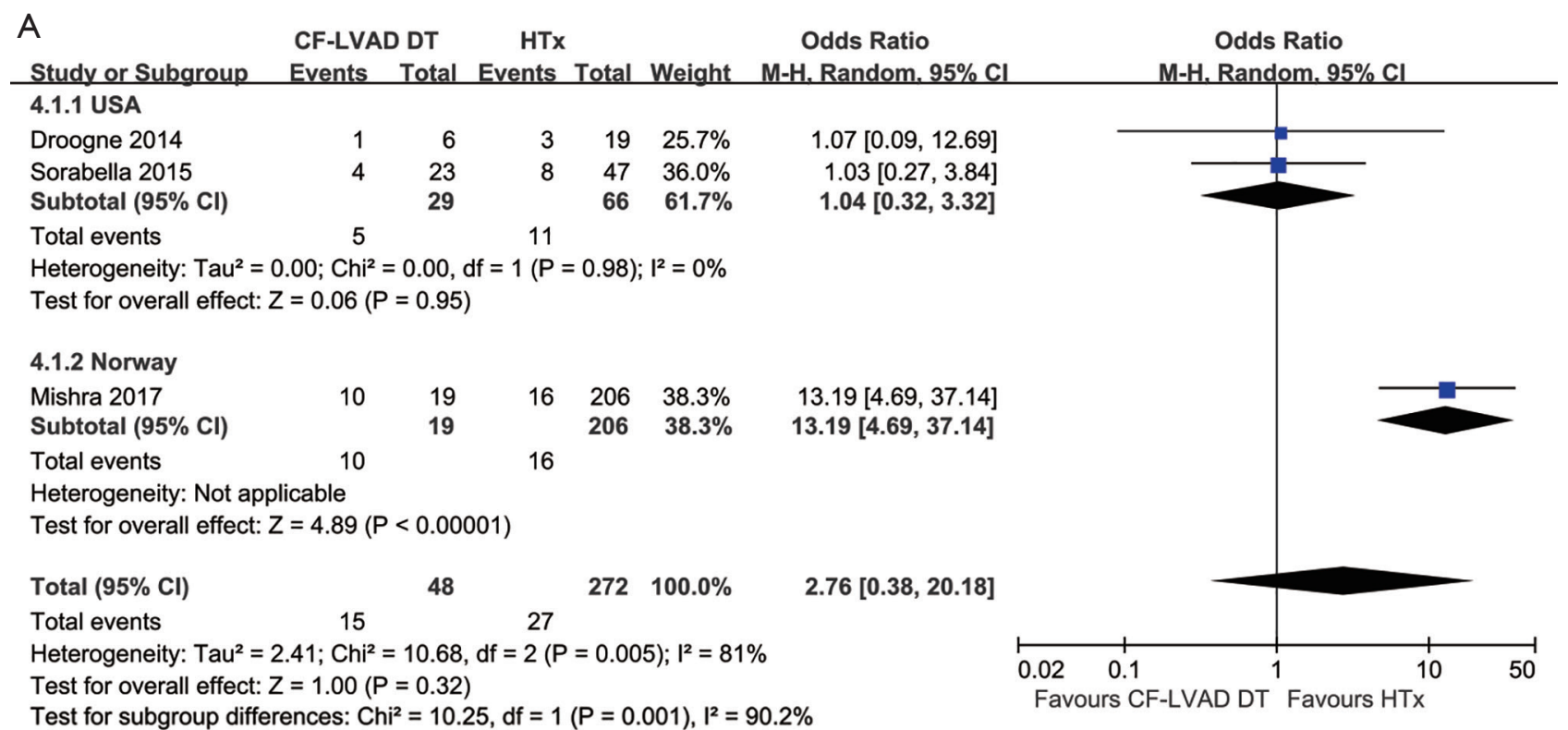

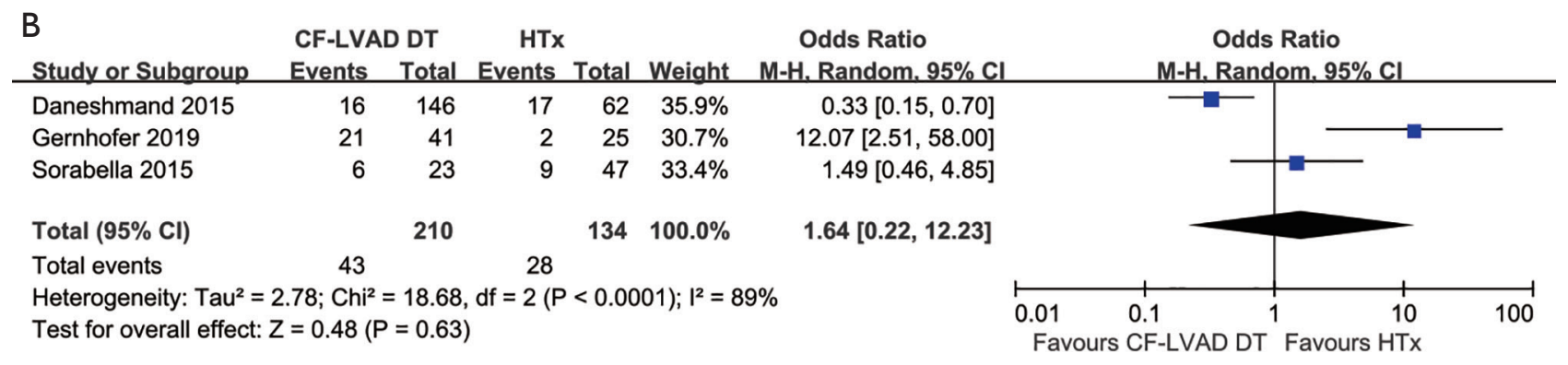

Figure 4 Forest plots for the mortality between CF-LVAD DT vs. HTx. (A) One-year mortality and (B) two-year mortality. CF-LVAD, continuous-flow left ventricular assist device; DT, destination therapy; HTx, heart transplantation; OR, odds ratio; CI, confidence interval.

Our meta-analysis showed similar one-year and twoyear mortality between CF-LVAD DT versus HTx. The centers varied in the initial time of performing the LVAD implantation, leading to differences in the experience of surgical techniques and patient management. Therefore, subgroup analysis was performed according to the country that was considered the main reason for data inconsistency in one-year mortality. Although we performed a comprehensive assessment of the available information, the heterogeneity of two-year mortality between DT and HTx is difficult to explain due to the limitation of published data in original articles. We assume that it is mainly related to differences in donor heart evaluation and use in various hospitals. Marginal donors with left ventricular hypertrophy, older age, long cold ischemic time or low left ventricular ejection fraction had adverse effects on post-transplant prognosis $(26,28)$. Due to the paucity of data on mortality or survival rates for over two years within included studies, the long-term outcomes after CF-LVAD as a DT versus HTx were not assessed. However, CF-LVAD as a DT was inferior to HTx with respect to longer survival rates, according to the database of the Interagency Registry for Mechanically Assisted Circulatory Support and the International Thoracic Organ Transplant Registry of the International Society for Heart and Lung Transplantation (24-27). The lower survival of CF-LVAD as a DT is linked to device-related complications and psychosocial disturbance (29,30). Considering devicerelated complications, apart from stroke, another important consideration is whether the aortic valve can tolerate the long-term hemodynamic changes after LVAD implantation is also a challenge for CF-LVAD as a DT (31). During 


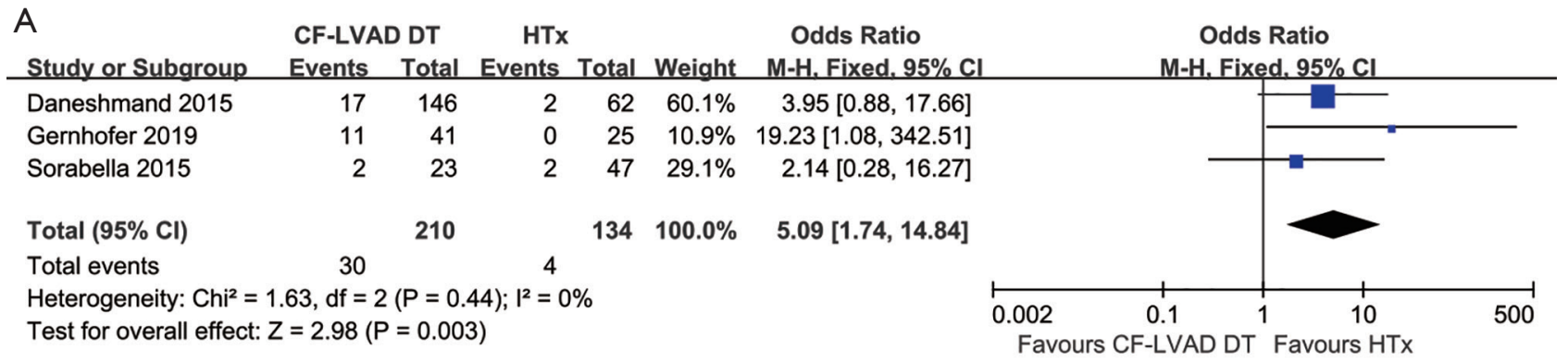

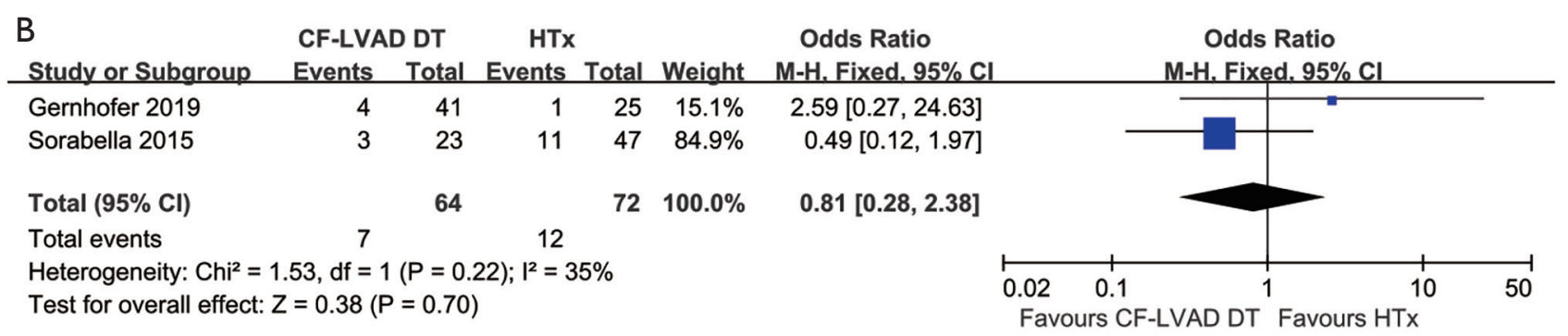

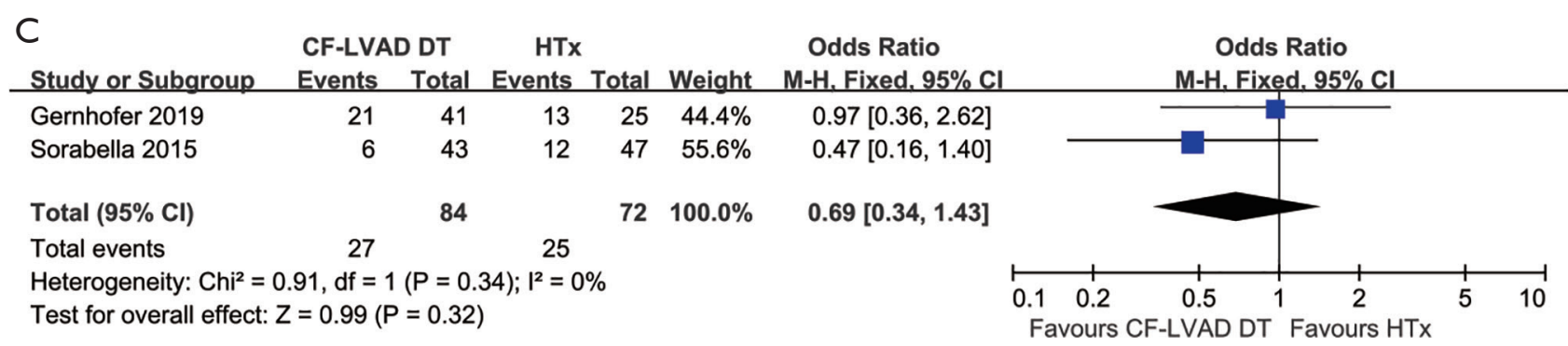

Figure 5 Forest plots for the adverse events between CF-LVAD DT vs. HTx. (A) Stroke, (B) bleeding, and (C) infection. CF-LVAD, continuous-flow left ventricular assist device; DT, destination therapy; HTx, heart transplantation; OR, odds ratio; CI, confidence interval.

LVAD support, aortic regurgitation may occur due to the excessive decrease in left ventricular pressure (32). Atkins et al. suggested that the aortic valve needed to be repaired or replaced if new-onset aortic valve insufficiency occurred during the LVAD support (33). On the other hand, some patients felt living life with LVAD as a DT did not meet their previous expectations of quality of life (34). Improving patient satisfaction with quality of life remains critically important, particularly for patients requiring long-term LVAD support. Close cooperation of telemedicine and remote monitoring could be beneficial to improve patients' quality with life and reduce psychosocial distress (35-37). With the continuous development of LVAD and the advancement of operative approaches, complications can be further reduced, so as to reduce the mortality of LVAD as a DT. The long-term outcomes for CF-LVAD as a DT remain to be defined in future studies.
CF-LVAD as a DT brought a higher risk of stroke and similar results of bleeding and infection compared with HTx. The higher incidence of stroke is associated with pump thrombosis and the duration of LVAD support. Longer duration of LVAD support increased the risk of stroke (38). In addition, the median waiting time for a donor heart was 6.9 months (39). In other words, many patients in CF-LVAD BTT can undergo HTx during LVAD support of less than a year duration. This is the main reason for our results demonstrating a higher incidence of stroke in CF-LVAD DT rather than in CF-LVAD BTT. Stroke, as a severe disabling complication, had negative effects on the quality of life and led to lower survival (38). Therefore, more strict control of anti-coagulant and antiplatelet therapy are required. Regarding adverse events, some studies have demonstrated that minimally invasive methods without sternotomy markedly promoted recovery 
and decreased partial complications $(40,41)$. However, the technical difficulty of minimally invasive methods limits their wide implementation. Further investigation is necessary to decrease the risks of devastating adverse events during long-term LVAD support.

\section{Limitations}

This study has several limitations. First, our meta-analysis is based on observational studies. Only a few studies compare the clinical results of LVAD implantation and HTx directly, most of which are case-control studies with information bias, selection bias, and confounding bias. Second, the criteria of the donor hearts differed among various centers. Third, meta-regression did not identify the factor of heterogeneity for two-year mortality between CF-LVAD DT and HTx. Lastly, long-term mortality after CF-LVAD as a DT versus HTx was not performed because of the paucity of adequate data.

\section{Conclusions}

In conclusion, CF-LVAD as a BTT results in similar outcomes as HTx within five years. CF-LVAD as a DT is associated with similar one-year and two-year mortality, but a higher risk of stroke, as compared with HTx. With the development of heart-assist devices and the emergence of new techniques, the long-term outcomes for CF-LVAD as a DT remain to be defined in future studies.

\section{Acknowledgments}

Funding: This work was supported by the Natural Science Foundation of Tianjin City (18JCZDJC36200 to Zhigang Liu).

\section{Footnote}

Conflicts of Interest: The authors have no conflicts of interest to declare.

Open Access Statement: This is an Open Access article distributed in accordance with the Creative Commons Attribution-NonCommercial-NoDerivs 4.0 International License (CC BY-NC-ND 4.0), which permits the noncommercial replication and distribution of the article with the strict proviso that no changes or edits are made and the original work is properly cited (including links to both the formal publication through the relevant DOI and the license). See: https://creativecommons.org/licenses/by-nc-nd/4.0/.

\section{References}

1. Ziaeian B, Fonarow GC. Epidemiology and aetiology of heart failure. Nat Rev Cardiol 2016;13:368-78.

2. Ponikowski P, Voors AA, Anker SD, et al. 2016 ESC Guidelines for the diagnosis and treatment of acute and chronic heart failure: The Task Force for the diagnosis and treatment of acute and chronic heart failure of the European Society of Cardiology (ESC)Developed with the special contribution of the Heart Failure Association (HFA) of the ESC. Eur Heart J 2016;37:2129-200.

3. Rose EA, Gelijns AC, Moskowitz AJ, et al. Long-term use of a left ventricular assist device for end-stage heart failure. N Engl J Med 2001;345:1435-43.

4. Cavarretta E, Marullo AGM, Sciarretta S, et al. A network meta-analysis of randomized trials and observational studies on left ventricular assist devices in adult patients with end-stage heart failure. Eur J Cardiothorac Surg 2019;55:461-7.

5. Kalya AV, Tector AJ, Crouch JD, et al. Comparison of Novacor and HeartMate vented electric left ventricular assist devices in a single institution. J Heart Lung Transplant 2005;24:1973-5.

6. Slaughter MS, Rogers JG, Milano CA, et al. Advanced heart failure treated with continuous-flow left ventricular assist device. N Engl J Med 2009;361:2241-51.

7. Rogers JG, Pagani FD, Tatooles AJ, et al. Intrapericardial Left Ventricular Assist Device for Advanced Heart Failure. N Engl J Med 2017;376:451-60.

8. Mehra MR, Uriel N, Naka Y, et al. A Fully Magnetically Levitated Left Ventricular Assist Device - Final Report. N Engl J Med 2019;380:1618-27.

9. Guglin M, Zucker MJ, Borlaug BA, et al. Evaluation for Heart Transplantation and LVAD Implantation: JACC Council Perspectives. J Am Coll Cardiol 2020;75:1471-87.

10. Stroup DF, Berlin JA, Morton SC, et al. Meta-analysis of observational studies in epidemiology: a proposal for reporting. Meta-analysis Of Observational Studies in Epidemiology (MOOSE) group. JAMA 2000;283:2008-12.

11. Ammirati E, Oliva FG, Colombo T, et al. Mid-term survival after continuous-flow left ventricular assist device versus heart transplantation. Heart Vessels 2016;31:722-33.

12. Daneshmand MA, Krishnamoorthy A, Samsky MD, et al. Comparison of two-year Outcomes of Extended Criteria Cardiac Transplantation Versus Destination Left 
Ventricular Assist Device Therapy Using Continuous Flow. Am J Cardiol 2015;116:573-9.

13. Deo SV, Sung K, Daly RC, et al. Cardiac transplantation after bridged therapy with continuous flow left ventricular assist devices. Heart Lung Circ 2014;23:224-8.

14. Droogne W, Jacobs S, Van den Bossche K, et al. Cost of one-year left ventricular assist device destination therapy in chronic heart failure: a comparison with heart transplantation. Acta Clin Belg 2014;69:165-70.

15. Gaffey AC, Phillips EC, Howard J, et al. Prior Sternotomy and Ventricular Assist Device Implantation Do Not Adversely Impact Survival or Allograft Function After Heart Transplantation. Ann Thorac Surg 2015;100:542-9.

16. Gernhofer YK, Braun OO, Brambatti M, et al. Which advanced heart failure therapy strategy is optimal for patients over 60 years old? J Cardiovasc Surg (Torino) 2019;60:251-8.

17. Mishra V, Fiane AE, Winsnes BA, et al. Cardiac replacement therapies: outcomes and costs for heart transplantation versus circulatory assist. Scand Cardiovasc J 2017;51:1-7.

18. Schumer EM, Ising MS, Trivedi JR, et al. Early Outcomes With Marginal Donor Hearts Compared With Left Ventricular Assist Device Support in Patients With Advanced Heart Failure. Ann Thorac Surg 2015;100:522-7.

19. Sorabella RA, Yerebakan H, Walters R, et al. Comparison of outcomes after heart replacement therapy in patients over 65 years old. Ann Thorac Surg 2015;99:582-8.

20. Suarez-Pierre A, Zhou X, Fraser CD 3rd, et al. Survival and Functional Status After Bridge-to-Transplant with a Left Ventricular Assist Device. ASAIO J 2019;65:661-7.

21. Williams ML, Trivedi JR, McCants KC, et al. Heart transplant vs left ventricular assist device in heart transplant-eligible patients. Ann Thorac Surg 2011;91:1330-3.

22. Yoshioka D, Li B, Takayama H, et al. Outcome of heart transplantation after bridge-to-transplant strategy using various mechanical circulatory support devices. Interact Cardiovasc Thorac Surg 2017;25:918-24.

23. Petroni T, D'Alessandro C, Combes A, et al. Longterm outcome of heart transplantation performed after ventricular assist device compared with standard heart transplantation. Arch Cardiovasc Dis 2019;112:485-93.

24. Kormos RL, Cowger J, Pagani FD, et al. The Society of Thoracic Surgeons Intermacs database annual report: Evolving indications, outcomes, and scientific partnerships. J Heart Lung Transplant 2019;38:114-26.
25. Fukuhara S, Takeda K, Polanco AR, et al. Prolonged continuous-flow left ventricular assist device support and posttransplantation outcomes: A new challenge. J Thorac Cardiovasc Surg 2016;151:872-80.e5.

26. Kobashigawa J, Khush K, Colvin M, et al. Report From the American Society of Transplantation Conference on Donor Heart Selection in Adult Cardiac Transplantation in the United States. Am J Transplant 2017;17:2559-66.

27. Khush KK, Cherikh WS, Chambers DC, et al. The International Thoracic Organ Transplant Registry of the International Society for Heart and Lung Transplantation: Thirty-sixth adult heart transplantation report - 2019; focus theme: Donor and recipient size match. J Heart Lung Transplant 2019;38:1056-66.

28. Khush KK. Donor selection in the modern era. Ann Cardiothorac Surg 2018;7:126-34.

29. Kilic A, Seese L, Pagani F, et al. Identifying Temporal Relationships Between In-Hospital Adverse Events After Implantation of Durable Left Ventricular Assist Devices. J Am Heart Assoc 2020;9:e015449.

30. Adams EE, Wrightson ML. Quality of life with an LVAD: A misunderstood concept. Heart Lung 2018;47:177-83.

31. Gustafsson F, Rogers JG. Left ventricular assist device therapy in advanced heart failure: patient selection and outcomes. Eur J Heart Fail 2017;19:595-602.

32. Rajagopal K, Daneshmand MA, Patel CB, et al. Natural history and clinical effect of aortic valve regurgitation after left ventricular assist device implantation. J Thorac Cardiovasc Surg 2013;145:1373-9.

33. Atkins BZ, Hashmi ZA, Ganapathi AM, et al. Surgical correction of aortic valve insufficiency after left ventricular assist device implantation. J Thorac Cardiovasc Surg 2013;146:1247-52.

34. Kitko LA, Hupcey JE, Birriel B, et al. Patients' decision making process and expectations of a left ventricular assist device pre and post implantation. Heart Lung 2016;45:95-9.

35. Hanff TC, Birati EY. Left Ventricular Assist Device as Destination Therapy: a State of the Science and Art of Long-Term Mechanical Circulatory Support. Curr Heart Fail Rep 2019;16:168-79.

36. Alotaibi S, Hernandez-Montfort J, Ali OE, et al. Remote monitoring of implantable cardiac devices in heart failure patients: a systematic review and metaanalysis of randomized controlled trials. Heart Fail Rev 2020;25:469-79.

37. Makdisi G, Makdisi PB, Bittner HB. How to establish a successful destination therapy ventricular assist device 
program. J Thorac Dis 2017;9:932-5.

38. Tsukui H, Abla A, Teuteberg JJ, et al. Cerebrovascular accidents in patients with a ventricular assist device. J Thorac Cardiovasc Surg 2007;134:114-23.

39. Colvin M, Smith JM, Hadley N, et al. OPTN/SRTR 2018 Annual Data Report: Heart. Am J Transplant 2020;20 Suppl s1:340-426.

Cite this article as: Zhang B, Guo S, Ning J, Li Y, Liu $Z$. Continuous-flow left ventricular assist device versus orthotopic heart transplantation in adults with heart failure: a systematic review and meta-analysis. Ann Cardiothorac Surg 2021;10(2):209-220. doi:10.21037/acs-2020-cfmcs-fs-197
40. Potapov EV, Krabatsch T. Minimally invasive continuousflow left ventricular assist device implantation: Avoiding a median sternotomy. J Heart Lung Transplant 2014;33:1199-200.

41. Mohite PN, Sabashnikov A, Raj B, et al. Minimally Invasive Left Ventricular Assist Device Implantation: A Comparative Study. Artif Organs 2018;42:1125-31. 
Table S1 NOS risk of bias scale for included studies

\begin{tabular}{|c|c|c|c|c|c|c|c|c|c|}
\hline \multirow[b]{2}{*}{ Studies } & \multicolumn{4}{|l|}{ Selection } & \multirow[b]{2}{*}{ Comparability } & \multicolumn{3}{|l|}{ Outcome } & \multirow{2}{*}{$\begin{array}{l}\text { Total } \\
\text { score }(0-9)\end{array}$} \\
\hline & $\begin{array}{l}\text { Representativeness of } \\
\text { the exposed Cohort }\end{array}$ & $\begin{array}{l}\text { Selection of the non- } \\
\text { exposed cohort }\end{array}$ & $\begin{array}{l}\text { Ascertainment of } \\
\text { exposure }\end{array}$ & $\begin{array}{l}\text { Outcome of interest not } \\
\text { present at start of study }\end{array}$ & & $\begin{array}{l}\text { Assessment of } \\
\text { outcome }\end{array}$ & $\begin{array}{l}\text { Adequacy of duration } \\
\text { of follow-up }\end{array}$ & $\begin{array}{l}\text { Adequacy of completeness } \\
\text { of follow-up }\end{array}$ & \\
\hline Ammirati 2016 (11) & 1 & 1 & 1 & 1 & 1 & 1 & 1 & 1 & 8 \\
\hline Daneshmand 2015 (12) & 1 & 1 & 1 & 0 & 2 & 1 & 1 & 1 & 8 \\
\hline Deo 2014 (13) & 1 & 1 & 1 & 0 & 2 & 1 & 1 & 1 & 8 \\
\hline Droogne 2014 (14) & 1 & 1 & 1 & 0 & 1 & 1 & 1 & 1 & 7 \\
\hline Gaffey 2015 (15) & 1 & 1 & 1 & 0 & 2 & 1 & 1 & 1 & 8 \\
\hline Gernhofer 2019 (16) & 1 & 1 & 1 & 0 & 1 & 1 & 1 & 1 & 7 \\
\hline Mishra 2017 (17) & 1 & 1 & 1 & 0 & 1 & 1 & 1 & 1 & 7 \\
\hline Schumer 2015 (18) & 1 & 1 & 1 & 0 & 1 & 1 & 1 & 1 & 7 \\
\hline Sorabella 2015 (19) & 1 & 1 & 1 & 0 & 2 & 1 & 1 & 1 & 8 \\
\hline Suarez-Pierre 2019 (20) & 1 & 1 & 1 & 1 & 1 & 1 & 1 & 1 & 8 \\
\hline Williams 2011 (21) & 1 & 1 & 1 & 1 & 2 & 1 & 1 & 1 & 9 \\
\hline Yoshioka 2017 (22) & 1 & 1 & 1 & 0 & 2 & 1 & 1 & 1 & 8 \\
\hline
\end{tabular}



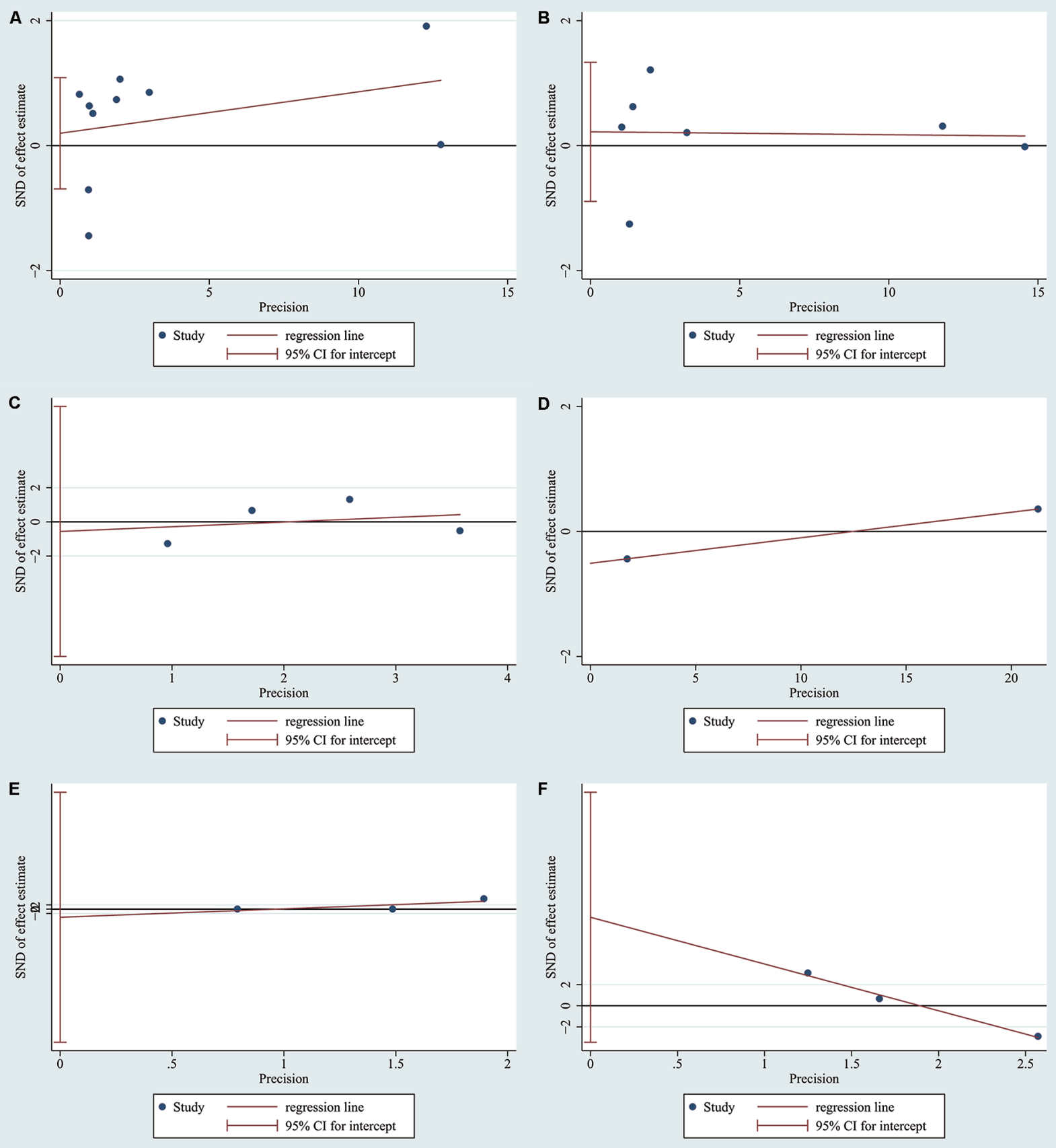

Figure S1 Egger's test for primary outcomes. (A) one-year mortality of CF-LVAD BTT vs. HTx, P=0.622; (B) two-year mortality of CFLVAD BTT vs. HTx, P=0.631; (C) three-year mortality of CF-LVAD BTT vs. HTx, P=0.773; (D) five-year mortality of CF-LVAD BTT vs. HTx, P=not available; (E) one-year mortality of CF-LVAD DT vs. HTx, P=0.560; (F) two-year mortality of CF-LVAD DT vs. HTx, $\mathrm{P}=0.07$. CF-LVAD, continuous-flow left ventricular assist device; DT, destination therapy; HTx, heart transplantation; OR, odds ratio; CI, confidence interval. 

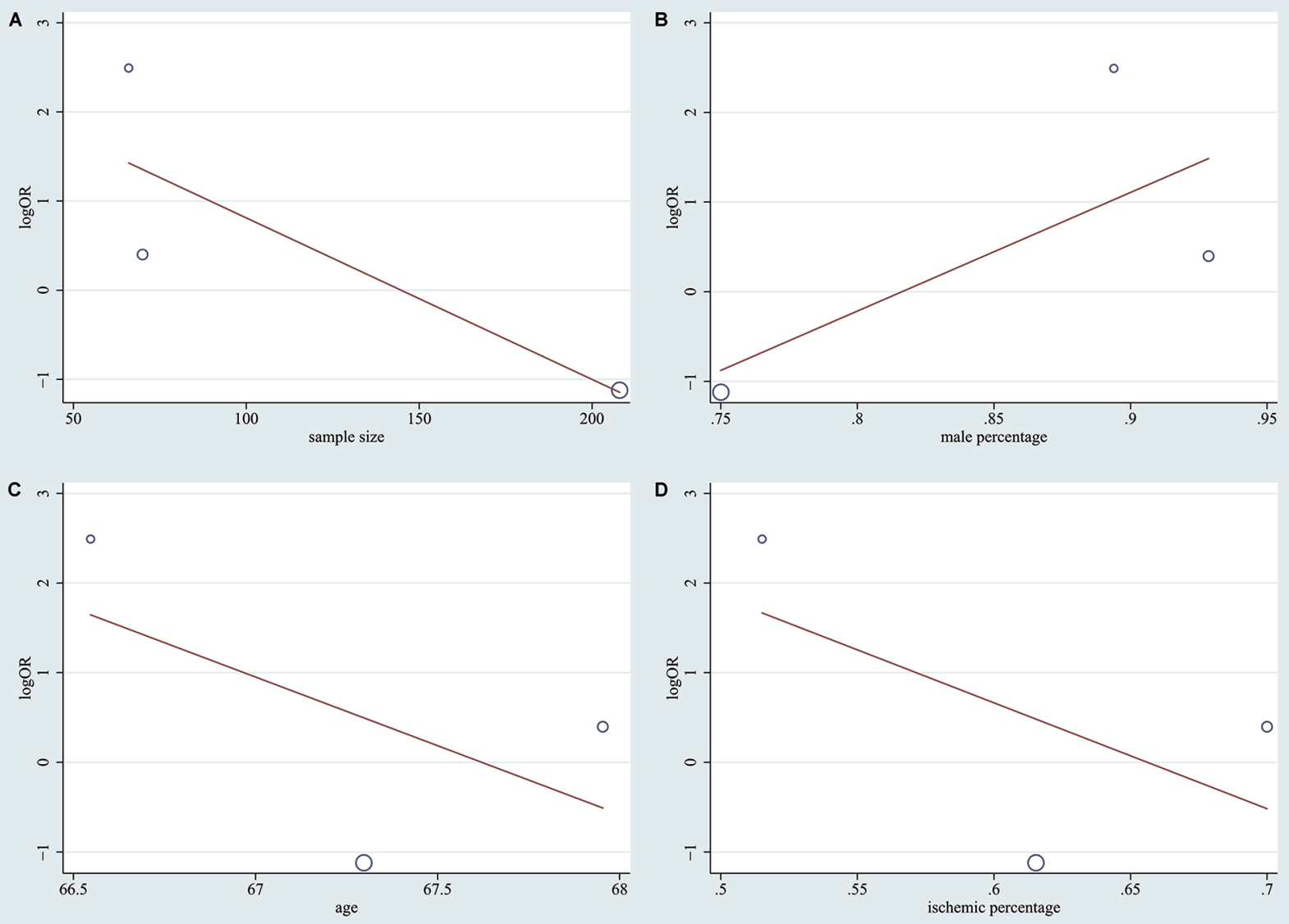

Figure S2 Meta regression for two-year mortality between CF-LVAD DT vs. HTx. (A) Sample size, (B) male percentage, (C) age, and (D) ischemic percentage had no effect on heterogeneity. CF-LVAD, continuous-flow left ventricular assist device; DT, destination therapy; HTx, heart transplantation; OR, odds ratio; CI, confidence interval. 